\title{
Study of Reciprocal Accountability and Total Quality Management in Education Sector and Its Ideal Implementation Towards Sustainable Development
}

\author{
Vijayan Gurumurthy Iyer \\ Professor in Civil Engineering, K.L.E.F. Deemed To Be University, Vijayawada, A-2/31, Kendriya Vihar-II, Paruthipattu, Avadi, \\ Chennai-600 071, India.
}

\begin{abstract}
Sustainable development (SD) is a kind of development that meets the needs of the present without compromising the ability and efficacy of future generations to meet their own needs [@25,26,27,28,29 Vijayan Gurumurthy Iyer, World Engineers' Convention(WEC) 2004, Shanghai, China]. Reciprocal accountability in education system is based on the performance assessment of competency-based education approach so as ensure the students achieve critical knowledge and skills. Continuous improvement in education system is an education system for education quality and performance that is everybody in the system from the capital to class room must be responsible for such of those aspects of education quality and performance that get controlled. Total quality management (TQM) or Continuous Improvements System (CIS) can be defined as set of systematic activities carried by an institution to efficiently achieve institutional objectives that satisfies beneficiaries at the appropriate time and price. TQM or CIS can be a comprehensive and structured approach to an educational management that seeks to improve the educational services through refinements in response to continuous feedback. Educational quality is defined as the totality of features and characteristics of services that bear on its ability and efficiency in terms of knowledge and character to satisfy a given or implied need. TQM of an education sector that shall achieve academic and research excellence and thus lead to SD. International Organizational for Standardization (ISO)'s 9000 standards focus continuous improvement system (CIS) or quality management (TQM) of all sorts of organizations. It defines the features on quality management system (QMS) that need to be in place to ensure that institutions identify and focus on improving areas where they have significant deficiencies. The objectives of this research, (i) To study of reciprocal accountability and total quality management in education sector and its ideal implementation towards sustainable development, (ii) to conduct action-based and field research on CIS to present QM ideas on education, (iii) to identify quality compliance requirements (QCRs) for an educational sector adherence to QM standards based on an educational research conducted on quality circles (QCs) duly launched in twelve educational institutions in south India and (iv) to promote sustainable policy recommendation to strengthen quality and quantity educational services. Education coupled with entrepreneurial process is an intricate SD process which is a targeted area of research to alleviate poverty from the emerging enterprising spirit. Output of the process is an international and national educational service to the beneficiaries concerning to both educational quality and quantity management TQM or CIS processes are divided into four sequential categories
\end{abstract}

such as plan, do, check, and act (PDCA cycle) for continuous process improvement. In the planning phase, educationalists define the problem to be addressed, collect relevant data, and ascertain the root cause of the academic problem; in the doing phase, educationalists develop and implement a comprehensive solution, and decide upon a measurement to gauge its and efficiency; in the checking phase, educationalists confirm the result through before-and-after data comparison; in the acting phase, educationalists document their results, inform others about process changes, and make recommendations for the problem to be addressed in the next PDCA cycle. It is concluded that CIS as a management approach of an educational institution centered on quality, based on the participation of all its members and aiming at long term success through beneficiary satisfaction and benefits to all members of the institution and society. CIS in an educational sector is based on quality management from the beneficiary's point of view. Based on this action-based and field research conducted on CIS or TQM, sustainable policy recommendation may be taken to strengthen both quality and quantity educational services concerned to both knowledge and character in educational sector. In the present article, importance of possible inclusion of CIS and steps involved for an implementation of framework in education sector are discussed.

Keywords-character; education; knowledge; management; policy; process; product; quality; quantity; learner; research; strength; sustainable national development; teaching

\section{INTRODUCTION}

Higher level educational institutions (HLEs) need to implement the educational values and quality improvement for the truth and pursue knowledge [1]. There must be specific focus given on the educational innovations, vision, mission and goals, guiding principles, environmental assessment, quality policies and principles, total quality management, technical knowledge, character, master plans for institutional growth, supply of value added knowledge based trained human power, obtaining feedback from stakeholders and for continual improvement, quality innovations in management and information communication technologies (ICT).

About 88\% economic growth is created by innovation [2]. To achieve this level, literacy rate should be high. It is necessary to take considerable steps to achieve socioeconomic development by tapping educational and entrepreneurial resources. To ensure socio-economical 
transformation, there main input resources which are innovation in quality and quantity of education coupled with entrepreneurship, sustainable development, educational research and total quality management methods. It has been found that there are considerable lags in quality management system right from the school education to teacher education and higher educational institutions that are important dependent parameter concerning to increase the literacy level. This research paper discusses such fulfilment of lags highlighting an importance of total quality management in an education sector and its implementation framework towards SD. The A.K economic model for certain output level of economic growth is the product of engineering or technical factor level (A) and the capital (K) [3]. Therefore, the solution is the creation of new sustainable enterprises by innovation. As per the standard production function discussed in the paper, the development of new knowledge is a crucial factor for economic growth as certain educational innovation level is required in engineering or technical systems. The economic growth is hereby explained by three factors as given below: -

1. The natural increase in the accumulation of labour potential [4],

2. Capital accumulation or money with which a business is being started and run,

3. Technological momentum (also called as total factor productivity (TFP) or efficiency in industrial processes.

The increase of labour and the capital accumulation be account for 12 percent of the economic growth, but the knowledge emerged that is coming from outside economy is described as technological change that is approximately account for about 88 percent [4]. The fundamental entrepreneurial momentum keeps the capital development dynamic which comes from the new enterprise creation process, new goods or service requirement from customers, the new methods of production and processes, new transportation, and new markets and new forms of an industrial organization.

Standard Production Function (SPF) of CIS is expressed as $\mathrm{Y}=\mathrm{f}(\mathrm{C}, \mathrm{L})$

where $\mathrm{Y}=$ Output, $\mathrm{C}=$ Capital, and $\mathrm{L}=$ Labour

As knowledge is an important factor for the economic growth,

Process Production function, (PPF)

$\mathrm{Y}=\mathrm{f}\left(\mathrm{X}_{1}, \mathrm{X}_{2}, \mathrm{X}_{3} \ldots \mathrm{Xn}\right)$

Standard Production Function (SPF) is modified as

$\mathrm{Y}=\mathrm{A}(\mathrm{C}, \mathrm{L}) \mathrm{f}(\mathrm{C}, \mathrm{L})$

' $A$ ' represents Knowledge and character on

Sustainable engineering or technical system ,

$\mathrm{Y}=$ Output ,

$\mathrm{C}=$ Capital

$\mathrm{L}=$ Labour

$\mathrm{f}=$ Standard production function

Hence the development of new knowledge is a crucial factor for the sustainable economic growth. As per the given standard production function, knowledge and character is a decisive production variation [5].

\section{OBJECTIVES OF THIS RESEARCH}

(i) Study of reciprocal accountability and total quality management in education sector and its ideal implementation towards sustainable development,

(ii) to conduct action-based and field research on CIS to present QM ideas on education, (iii) to identify quality compliance requirements (QCRs) for an educational sector adherence to QM standards based on an educational research conducted on quality circles (QCs) duly launched in twelve educational institutions in south India and (iv) to promote sustainable policy recommendation to strengthen quality and quantity educational services.

\section{AsSociated OBJEctives}

1. To identify and evaluate present educational problems in educational sector;

2. To provide solution for the various problems encountered with special reference to :-

(i) Conduction of quality improvement (QI) programs for faculty to enrich techno-pedagogue skills, professional and research training requirements, the conduction of innovative add-on courses (QIPs) and research-oriented courses, and workshop.

(ii) Updating faculty competency profile and comprehensive performance assessment and evaluation,

(iii) Defining workload norms for faculty employed in lower and Higher Learning Institutions,

(iv) Updating comprehensive profile for the Science, Humanity, Engineering and Technological faculty.

(v) To incorporate industrial oriented courses in Curriculum,

(vi) To formulate and appraise innovative in-service and pre-service and post-service faculty development programs (FDPs).

(vii) To improve the research productivity of faculty and quality of lectures in educational institutions,

(viii) To promote conduction of feasible experiments in education sector by investigation devises.

3. To implement Total Quality Management (TQM)/CIS concepts in an educational sector,

4. To inculcate innovation in educational sector through research publications and citations;

5. To promote the concept of sustainable entrepreneurship education in education sector;

6. To promote environmental education in an education sector as environmental science, solid and hazardous waste management, sustainable entrepreneurship, sustainable development and total quality management are the basis of environmental education in this century.

7. To fulfil the following academic missions [5]:

(i) Problem focused education 
(ii) Research oriented programmes

(iii) Interdisciplinary approach;

(iv) Experiential learning and training approach

\section{Materials And MEthods}

The author has conducted action-based and field research trials on CIS to present QM ideas for education and quality compliance requirements (QCRs) for an educational sector adherence to established ISO standards based on an educational research conducted on quality circles (QCs) duly launched in twelve educational institutions in south India. As per educational statistics study revealed that a person receives one-fourth of education from teacher, another fourth by own intellectual efforts, another fourth from fellow people and the rest during time through life experience [6]. An entrepreneur learns from life experience of education. The subtle relationship between education and entrepreneurship is an intricate process that need to be inculcated in our educational system to benefit more from the emerging sustainable enterprises spirit [7]. Entrepreneurial process is set of entrepreneurial activities that are interacting and inter-relating each other [8]. That is quality in terms of relevance and degree of academic excellence and quantity in terms of number of elements access to these activities.

\section{TOTAL QUALITY MANAGEMENT /CIS IN AN EDUCATION SECTOR}

Total Quality Management (TQM) or CIS concepts consisting of institution -wide efforts to establish permanent a climate for continuously improving its ability, efficiency and values to deliver high-quality educational services to the beneficiaries [9].

CIS requirements for an educational sector adherence to established standards such as International Organizational for Standardization's ISO 9000 series as given in figure mentioning the process approach in an educational system. It defines that TQM or CIS as a management approach of an educational institution cantered on quality, based on the participation of all its members and aiming at long term success through customer satisfaction and benefits to all members of the institution and society. Hence, TQM or CIS is a process based on quality management from the beneficiaries' point of view as shown in figure 1 .

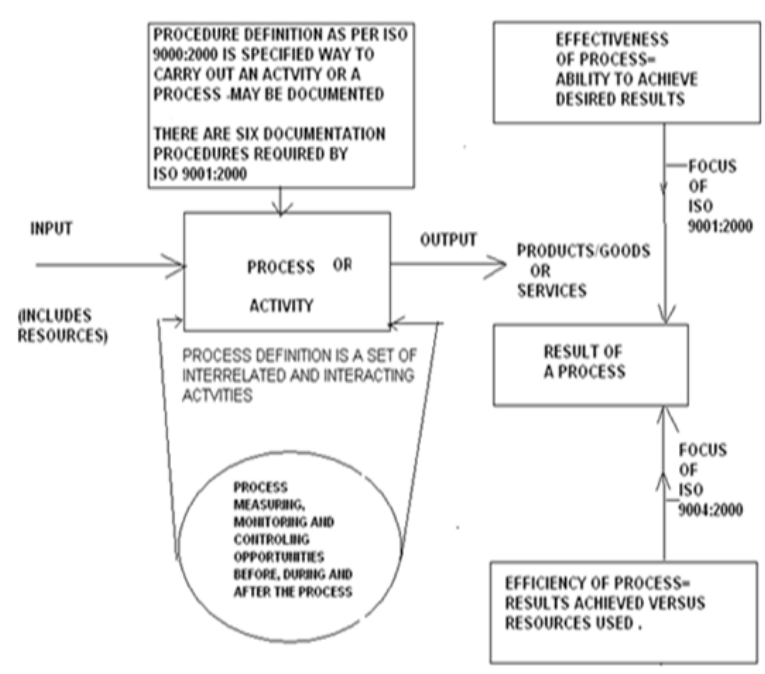

FIGURE I. SCHEMATIC REPRESENTATION OF A PROCESS

ISO 9000 series focus on quality management and defines the features of quality management system (QMS) that need to be established to ensure that educational sectors identify and focus on improving the areas where they have significant educational deficiencies. CIS techniques and various process analysis tools include statistical process control, zero defect process, lean manufacturing system and six sigma belt and international organization for standardization (ISO) standards such as ISO 9000, ISO 14000, ISO 18000 and ISO 50000 standards. Educational institutions must be able to implement TQM or CIS by following QM standards for sustainable educational development [10].

\section{QUALITY CIRCLES IN EDUCATIONAL INSTITUTIONS}

Quality circles (QCs) have been launched in Prince Dr. Vasudevan College of Engineering \& Technology (Affiliated to Anna University) at Chennai. QCs facilitate educational sectors to identify and solve the academic and research related problems. There is scope enhancement for the group based solution of academic and research related problems.

QC employs the following quality improvement (QI) tools:

Cause -and -Effect diagrams (Fishbone diagrams)

Pareto Charts

Data Collection through Check Sheets (Process Maps, Data gathering tools), Stratification of data.

Graphical tools such as Histograms, Frequency diagrams and Pie charts

Statistical Quality Control(SQC) and Statistical Process Control Charts (SPC) Charts

Scatter Diagrams and Plots and Correlation Analysis

Operation and Process Flow Charts

QCs have been adopted to prepare 'Total Quality People(TQP)' so as to promote SPC and SQC in academics and research for improvement of students' academic 
performance and personality development, teaching and learning process that include steps to improve results [11].

The class committee serves as a' QC' for the class. The course committee serves as QC for the course. University and college class committee consists of the concerned teacher, student representatives and a chairperson who is not teaching the class be formed for each class. QCs meet on a regular basis normally at two-week intervals of time for one or two hour's durations. Four or five meetings per semester have been conducted. The functions of the class committees are to identify academic and research problem faced by the students which must be taken up on priority. Problems are solved by basic problem-solving methods. Solutions for the problems are identified and evaluated. This creates and generates number of viable alternative solutions.

Hence, the class committees function towards addressing students' problem and solution, including assignment of weightage for various course modules of evaluation, identification of weak students and improving their performance, failure mode effect analysis (FMEA) and recommending necessary corrective action and preventive action by the faculty.

The students' absenteeism is the most widespread problem existing in the institution for a long time. By discussion in the QC and class room using brainstorming and other CIS tools, various causes and effects are evaluated. Late coming is a problem in educational institution. An attempt has been made to solve students' late coming problem by studying causes and effects. Steps to improve academic and research performance have been evaluated.

Iyer, Vijayan Gurumurthy has discussed an integrative approach in the paper entitled "Education Coupled with Entrepreneurial Process Approach Towards Sustainable Development" which has been included in Abstracts \& Proceedings Book of the Global Conference on Contemporary Issues in Education (ISSN: 18770428) organized by the Academic World Education and Research Center, www.awercenter.org, at Las Vegas, USA during 12-14, July 2014 duly $\begin{array}{llll}\text { published by Elsevier } & \text { B.V. }\end{array}$ http://www.globalcenter.info/globe-edu/wpcontent/uploads/2013/06/GLOBE-EDU-2014-Abstracts-

Book.pdf, pp.17, 32-33. Sustainable entrepreneurship is an integrative approach based on entrepreneurship and innovation management. It focuses in depth understanding aspects as idea generation, science, engineering and technology-based entrepreneurship, marketing and markets, organization and project management, new sustainable product and process development, entrepreneurial finance, human resource development and operations [12]. This is called special education which will be encouraged to combine and apply students' creativity and innovation to design and develop science, engineering or technology and environment-based idea. The objective of an educations sector is to introduce the concept, issue, and theme related to business planning, strategy, and entrepreneurship as well as the functional activities in a sustainable business venture such as guidelines to set up an entrepreneur and become a successful entrepreneur. It is necessary to explore such business planning and strategic management issues of engineering or technology driven enterprises in the initial stages of development. Business analysis and planning skills are developed in this course.

The beneficiaries will be encouraged to assess and evaluate their potential for entrepreneurial careers and develop attitudes and skills that will be useful in engineering or technological new ventures.

1. Learn and understand market identification and assessment techniques

2. Guidance on how to develop new business idea and successful business plan preparation.

3. Fundamental of finance and marketing

4. Intellectual property protection

5. Soliciting funds

6. Successful business partnership

7. Preparation of Detailed Project Reports (DPRs)

\section{Project implementation schedule.}

"Sustainable entrepreneurship" is a kind of entrepreneurship that meets the needs the present without compromising the effectiveness, efficiency and values of future generations to meet their own needs [12]. A person who sets up and runs successfully a small, medium or large-scale enterprise or business at considerable risk is an entrepreneur. The entrepreneur combines efficiently six kinds of input resources, viz., capital, man power, market, machineries, raw materials and method to transform manufacture of output goods, products or provide services. An entrepreneur is thus who organizes, manages, assumes risks and enjoys profits of enterprise or business successfully. A sustainable entrepreneur propels entrepreneurial growth through innovation. Environmental entrepreneur considers the environment in organizational planning and decision making and to arrive at actions which are more environmentally and socially compatible. The concept of sustainability is highlighted when one works in a manner that resources do not get depleted due to business endeavors. Hence, implementation of this concept enables final year undergraduate course students to become successful new entrepreneurs [12].

\section{EDUCATIONAL RESOURCE PlanNing (ERP) - A SOFTWARE FOR COMPUTER BASED EDUCATION}

Enterprise Resource Planning (ERP) is a software that helps to integrate nearly all the functions of an educational institution enabling to plan, track and see its resources in the best viable way to receive its customers [13]. The resources are (1) faculty and staff that is man power, (2) Infra structure facilities that is machine power, (3) sustainable educational methods, (4) educational materials, (5) capital budgeting and financial resources and (6) market to meet supply and demand of value added trained human power.

ERP effectively integrates the islands of information within the educational institution. 
The sustainable methods and educational materials including self-learning entrepreneurial materials (SLEM) have been employed. Since there is considerable educational growth in terms of quantity in Schools, Universities and Colleges, there is an unsustainable growth of infrastructures. As per an educational survey, only, about $66 \%$ of the faculty members possess master's degree in their respective disciplines. More than $90 \%$ of them do not have sufficient industrial and field experience in teaching and research. Hence it is required for them to improve their standard of education to master's and doctorate degree as well research level [13].

To develop faculty various innovative methods such as quality improvements (QI) programs, flexible QI programmes, faculty development programmes, in-house QI programmes, distance-cum-contact courses, summer and winter schools, and part-time programs must be conduct in teacher educator institutions in regular intervals of time. It has been observed that participants in such programmes are very less. Faculty must be provided with sufficient career opportunities to improve upon their qualifications through the quality improvement (QI) programs to get them imparted technoscientific pedagogical skills and professional training requirement including research expertise. Under the quality improvement programs (QIP), a variety of short term courses need to be imparted to meet the sustainable training needs for all levels of faculty.

The educational sector should incorporate three methods, viz., [1] Total Quality Management, [2] Peer Review and Evaluation, and [3] Sustainable Assessment and Accreditation by a competent educationalist or peer organization.

Sustainable research provides efficient methods and educational innovations to improve the research and teaching productivity of faculty and quality of lectures at par with the international academic excellence in an educational sector [14]. The quality and quantity management system standards including internal academic audits may be practiced in schools, teacher education and higher educational institutions. CIS elements are given below:

\section{Requirements of scientifically trained human power}

2. Quality circles in educational institutions

3. To specify faculty workload norms and workload distribution per week;

4. Preparation of lecture plans (yearly/semester wise, weekly \& daily), lesson action plans for Theory, and laboratory practice;

5. Self-assessment Report by the faculty for each day's progress (work diary) provided in Table. Reporting weekly summary report by the teacher given in Table

6. Requirements for the structure of the classroom lecture and quality of lectures.

7. Methods for preparation of the lecture notes and research methods for preparation of lecture notes supplement. Updated research information from internet. Video lecture programmes.

\section{Computer oriented e.based education.}

9. Setting up of comprehensive performance-based appraisal system for the faculty called academic and research performance indicator

10. Training and development of teacher-educator

11. ACADIS (Academic Information System), teaching slots and faculty credit log concepts.

\section{Sustainable entrepreneurial education.}

13. Importance of environmental education in an education sector as Environmental Science and the Sustainable Development and total quality management are the basis of environmental education of this century for the quality of life.

\section{VALUES DRIVEN QUALITY MANAGEMENT (VDQM) SYSTEM APPROACH}

Culture must be realized for quality and productivity within an educational sector [15]. Quality management (QM) is defined as a set of systematic activities carried out by the entire institution to effectively and efficiently achieve institutional objectives to provide educational services with a level of quality that satisfies customers at the appropriate time and cost. QM is the culture of an institution committed to customer satisfaction through continuous improvement. By supplementing the QM with the culture which continuously incorporate educational values into the management of quality in an educational sector. That is by superimposing the culture cycle on the QM cycle shall create and generate the values driven QM (VDQM) cycle as shown in figure 2.

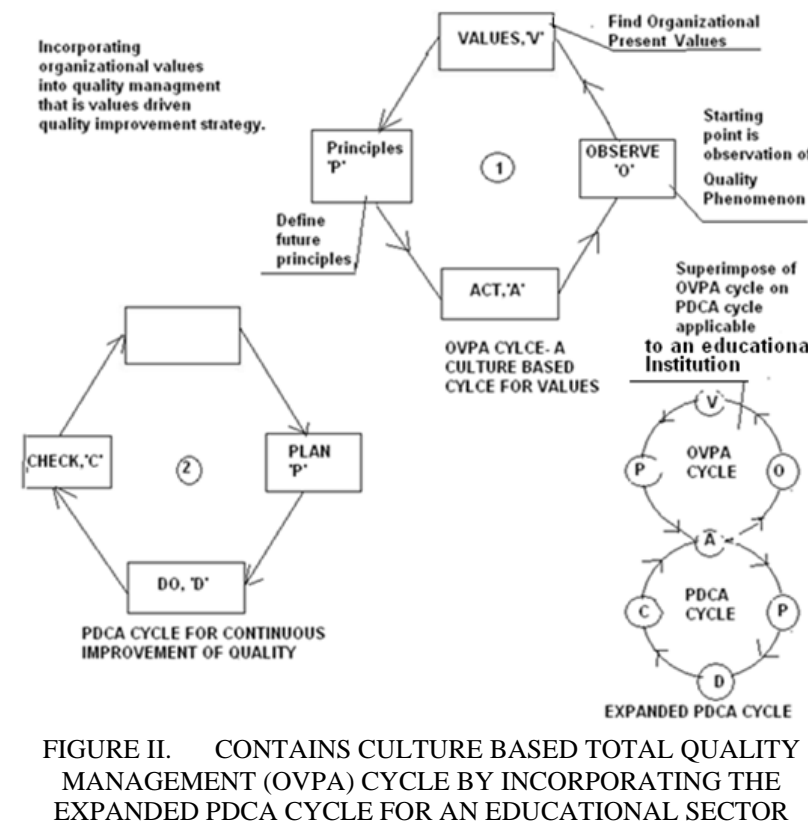

VDQM system is a culture based comprehensive and structured approach to an educational management that seeks to improve the values and quality of educational services through ongoing refinements and incorporating educational values in response to continuous feedback. By implementing 
VDQM in an educational sector shall succeed sustainable development. Sustainable development can be defined as a kind of development that meets the needs of the present without compromising the ability, efficiency and values of future generations to meet their own needs. VDQM is defined as values driven quality management system approach of an educational institution centered on quality and values based on the participation of all its members and aiming at long term success through customer satisfaction and benefits to all members of the institution and society. The approach is based on values driven quality management from the stakeholder's point of view. VDQM processes are divided into eight sequential categories: plan, do, check, act, observe, values, principles, and act. VDQM will be based on the integration of PDCA (plan, do, check, act, observe) cycle and OVPA (observe, values, principles, and act) cycle. This combined cycle is also called the expanded Deming's cycle for deriving culture oriented continuous process improvement. In the planning phase, educationalists define the problem to be addressed, collect relevant data, and ascertain the problem's root cause; in the doing phase, educationalists develop and implement a solution, and decide upon a measurement to gauge its values, effectiveness and efficiency; in the checking phase , educationalists confirm the result through before-andafter data comparison; in the acting phase, educationalists document their results, inform others about process changes, and make recommendations for the problem to be addressed in the next OVPA cycle or culture's cycle for incorporating values. Culture processes are divided into four sequential categories: observe, values, principles, and act. In the observation phase, educationalists observe present quality related phenomena of educational services; in the values phase, educationalists find present values of the educational services; in the principles phase, educationalists define future principles and in the acting phase, educationalists document their overall results, inform others about process changes, and make recommendations for the problem to be addressed in the PDCA cycle. ISO 9000 series focus on quality management for all sorts of manufacturing and service organizations. The features of quality management system (QMS) standards are established to ensure our educational sector identifies and focuses on improving the areas where they have significant educational deficiencies. In the present article, importance of VDQM in an educational sector has been discussed. VDQMS standards and their compliance requirement (CR) with respect to higher and lower learning institutions (HLIs and LLIs) have been discussed such as International Organization for Standardization's ISO 9000 series, ISO 14000 series, ISO 50000 series, ISO 18000 series and by continuously working with culture-based quality policies our educational institutions automatically become part of the quality management (QM) process [16].

\section{RESUlTS}

Given below results and discussions provided which were based on the conduction of action-based and field research on CIS conducted in twelve educational institutions in south India.

\section{A. Result of Comprehensive Academic and Research Performance Appraisal System}

A performance-based appraisal system for teachers should be setup in educational institution well integrated with institutional functioning and this should lead to the identification of individual training and research and development needs [17]. This should also enable the identification of teachers whose performance is outstanding. Such performances and excellence should be well recognized and rewarded. All teacher educational institutions should introduce a system for performance appraisal. The performance report should comprise the data such as publication of refereed research papers of faculty, paper reading in seminars / refereed conference, publication of books, research citations, citation indexed database (CID), research contributions, biographical reference books, patents, innovations, inventions and refereed discoveries. This system should be followed by the management for career advancement of faculty in their institutions.

\section{B. Discussions}

Educational Resources Planning (ERP) Software's

Why is ERP Required?

(1) Speed of the teaching-learning process

(2) Monitoring, measurement and control opportunities in educational environment

(3) Innovation in education and entrepreneurship.

Approach to ERP Implementation - A Road Map

Road Map for successful implementation of ERP

1. Clear Management Commitments

2. Top class ERP leadership

3. ERP only after process improvement

4. Training to implementation task force and user group

5. Right choice of ERP packages

Four options for developing ERP Packages

1. Developing an own ERP package (in-house development)

2. Modifying and enhancing the capabilities of the existing system

\section{Buying readymade package}

4. Engaging a software company

\section{Correct Approach to ERP Software}

The options are dependent upon strategic planning and decision-making process and need a substantial capital investment. Right option must be selected only after evaluating the cost-benefit analysis [18]. 


\section{Discussions on Quality Circles in Educational Institutions}

Quality circles (QCs) have been launched in Prince Dr. Vasudevan College of Engineering \& Technology (Affiliated to Anna University) at Chennai during investigation period. QCs facilitate educational sectors to identify and solve the academic and research related problems. There is scope for the group-based solution of academic related problems.

QC employs the following quality improvement (QI) tools:

1. Cause -and -Effect diagrams (Fishbone diagrams)

2. Pareto Charts

3. Data Collection through Check Sheets (Process Maps, Data gathering tools), Stratification of data.

4. Graphical tools such as Histograms, Frequency diagrams and Pie charts

5. Statistical Quality Control(SQC) and Statistical Process Control Charts (SPC) Charts

6. Scatter Diagrams and Plots and Correlation Analysis

\section{Flow Charts}

QCs have been adopted to prepare 'Total Quality People(TQP)' to promote SPC and SQC in academics and research for improvement of students' academic performance and students' personality development, teaching and learning process which include steps to improve results.

\section{E. Discussions on Computer Based e.education Process}

There are timetabling, scheduling software have been designed to use the available teaching resources effectively. Each faculty must maintain a course page descriptive and notify web URL address to the students. Lesson plans for theory, tutorial and practice shall be prepared and uploaded in website including lesson plans, lecture notes, supplements. These locations or pages can also display students' attendance, test marks, and assignments. There shall be a class group or course group for each subject and these e-group members having mail ID communicated though e-mail compulsory.

Given below concept of Academic Information System (ACADIS), Teaching Slot Concept (TSC) and Faculty Credit Log Concept (FCLC) to efficiently manage academic courses conducted for the various classes at all levels [19].

\section{ACADIS, Teaching Slot and Faculty Credit Log Concept}

Step-1: Preparation of academic information system; -

Details of Academic courses are prepared which is called Academic Information system (ACADIS) during trimester / semester.

1. One lecture hour per week is rated as one credit hour.

2. Two tutorials or two practical hours per week are rated as one credit.

\section{Example: - How to prepare the ACADIS}

Step II: Preparation of teaching slots: -

This is the one page information which shows the teaching slots of the faculty and free time slots (FTS).

1 . The teaching workload is calculated as in terms of credit based contact hours.
2. One lecture hour per week is rated as one credit hour.

3. Two tutorial or two practical hours per week are rated as one credit.

4. The conduct hour is sum of theory tutorial and practical hours.

5. The conduct hour is interpreted as "One hour of practical/ tutorial classes is treated as one hour of lecture".

6. The departmental codes are identified in three letters.

7. The number of teaching slots is prepared as one line statement.

For example a teaching slot statement mentioned below is interpreted as

\section{ECE4A- EC402-T1-3.5-ECE-SLT}

ECE4A is the Branch code / semester / Sub-section

EC402 is the Subject code entitled

“Transmission lines and Wave guides" T1 is the main teacher / T2 is second assisting teacher / T3 is Third assisting teacher.

D1TI is Day 1 main teacher/ D1T3 is Day I third assisting teacher.

3.5 is the credit hours of the individual teacher

ECE is the handling department

SLT is the mnemonic of handling teacher.

Example: - How to prepare the Teaching Slots

TABLE I. TEACHING SLOTS OF DEPARTMENT EVEN SEMESTER

\begin{tabular}{lll}
\hline Texhing Slos & S.No & Teaching Slots \\
\hline BCEAA-EC402-T1-3.5ECE-SLT & 35 & ECB6-6E1-D2T-225-ECE-ASL \\
ECE4A-EC403-T1-3.5ECE-DKS & 36 & ECB6-6E1-D2T2-15-BCE-AKT \\
\hline
\end{tabular}

Step- III: Faculty credits log concept: The teacher individual Teaching Workload and Projects Workload are given in credits.

F. Environmental Science and Sustainable Development are the Basis of Environmental Education and Research (EER) towards Sustainable National Development

Environmental education and research is a new multidisciplinary aspect with implemented ecological philosophy and ecological ethics, establishing New Civilization Sustainable Development through a new subject Environmental Science [20]. This signifies a new education. New civilization requires innovative approaches to education that will be educated in "Modern Research Universities and Colleges and Schools which have a unique and important role. This means information, knowledge and understanding of the following significant fields: a) in the concept of sustainable development- knowledge of the basic principles: precaution, risk prediction, prevention of causes, new assessment of the environment, changed behavior, changed methods of consumption and the establishment of the necessary demographic institutions and processes, b) in ecology, main principles , laws, definitions and terminology, c) basic factors 
of the environment, air , water, soil, solid waste, bio-diversity, the circles of matter, d) sources and methods of risk introduction to the environment e) Impact of old technologies and fundamental knowledge in the new technologies and other solutions in different fields outside the profession. New education is necessary which will be carried out from two aspects, (i) interwoven through all professional subjects and (ii) synthetic multidisciplinary by the integrating subjectEnvironmental Science and Sustainable Development [21]. Based on experience in transferring the knowledge in the field of (i) Environmental Science and (ii) Sustainable Development to the students at several faculties, that the last two semesters of University education in all disciplines of science, engineering and technology should include the course "Environmental Science", Environmental Impact Assessment, Total Quality Management, and "Sustainable Development" $[22,23]$. The last year of studies is most suitable because till that time the student has acquired knowledge in different domains of his profession, so with the study of Environmental science and sustainable development, the student synthesize knowledge [24]. The course should cover approximately two lessons per week and two lessons for the discussion on the preparation of the essay and individual seminar paper [25, 26, 27,28,29 @Vijayan Gurumurthy Iyer, World Engineers' Convention (WEC) 2004, Shanghai, China].

\section{CONCLUSION}

Reciprocal accountability in education system is based on the performance assessment of competency-based education approach so as ensure the students achieve critical knowledge and skills. Continuous improvement in education system is an education system for education quality and performance that is everybody in the system from the capital to class room must be responsible for such of those aspects of education quality and performance that get controlled.

Sustainable development (SD) is a kind of development that meets the needs of the present without compromising the ability and efficacy of future generations to meet their own needs. Total quality management or CIS can be defined as a set of systematic activities carried by an institution to efficiently achieve institutional objectives that satisfies beneficiaries at the appropriate time and price.

The research objectives has been focused on study of reciprocal accountability and total quality management in education sector and its ideal implementation towards sustainable development,

(ii) to conduct action-based and field research on CIS to present QM ideas on education, (iii) to identify quality compliance requirements (QCRs) for an educational sector adherence to QM standards based on an educational research conducted on quality circles (QCs) duly launched in twelve educational institutions in south India and (iv) to promote sustainable policy recommendation to strengthen quality and quantity educational services.

As per educational statistics study revealed that a person receives one-fourth of education from teacher, another fourth by own intellectual efforts, another fourth from fellow people and the rest during time through life experience. An entrepreneur learns from life experience of education. The subtle relationship between education and entrepreneurship is an intricate process that needs to be established in educational sector to benefit more from the emerging sustainable enterprises spirit to alleviate poverty and sustainable development.

Entrepreneurial process is set of entrepreneurial activities interacting and inter-relating each other. That is quality in terms of relevance and degree of academic and research excellence and quantity in terms of number of elements accessing to these activities. The development of new knowledge is a crucial factor for the sustainable economic growth. As per the given standard production function, knowledge and character is a decisive production variation. The educational sector should incorporate three systematic methods, viz., [1] Total Quality Management, [2] Peer Review and Evaluation, and [3] Sustainable Assessment and Accreditation (SAA) by a competent educationalist or peer organization.

VDQM system is a culture based comprehensive and structured approach to an educational research management that seeks to improve the values and quality of educational services through ongoing refinements and incorporating educational values in response to continuous feedback. By implementing VDQM in an educational sector shall succeed sustainable development.

A comprehensive performance-based appraisal system for faculty should be setup in educational institution well integrated with institutional functioning and this should lead to the identification of individual training and research and development needs.

Based on this action-based and field research conducted on TQM or CIS, sustainable policy recommendation may be taken to strengthen both quality and quantity educational services concerned to both knowledge and character in educational sector. It is need of the hour to promote environmental education and research in education sector as Environmental science and sustainable development are the basis of sustainable education in this 21 st Century.

\section{ACKNOWLEDGMENT}

The author conveys his gratitude to the Organizers of 2018 2 nd International Conference on Applied Mathematics, Modelling and Statistics Application (AMMSA2018 for TPC service acceptance as AMMSA General Chair of the Committee and for publication of this research chapter by Atlantis Press in the book entitled "Advances in Intelligent Systems Research” (ISSN 1951-6851).

\section{REFERENCES}

[1] Gail M.Gallitant et., (2009), “The Content and Format of a Professional Development Program and its Attitudinal Effect on Teachers of Mathematics in WSEAS Proceedings of the International Journal of Education and Information Technologies Issue 3, Volume 5, 2011, pp. 336-343.

[2] Vijayan G. Iyer, et al, (2012),“ Environmental Process Based Education and Research for Better Life and Enactment of International Environmental Impact Laws-2012, "Models and Methods in Applied 
Sciences”, In Proceedings of the 2 nd International Conference on Environment, Economics, Energy, Devices, Systems, Communications, Computers, Mathematics (EDSCM'12) (ISBN: 978-1-61804-0824).International Authority for the Advancement of Science and Applications of Technology (IAASAT), April 2-4, 2012 at Saint Malo\& Mont Saint-Michel, France, pp.44-56.

[3] Vijayan G. Iyer, (2011), “Environmental Process Based Education and Research for Better Life and Enactment of International Policy Act on Environment 2011. Book of Proceedings of the World Forum International Congress, "Natural Cataclysms and Global Problems of the Modern Civilization”, GEOCATACLYSM-2011 (ISBN 978-9952-45114-6),19-21, publishers SWB-International Publishing House 2012, London, September 19-21, 2011, Istanbul, Turkey, SWB London, 2012, 621 p., International Committee on Global Geological Change and Environmental Changes Geo Change , pp. 565-566.

[4] Vijayan G. Iyer, (2011)Recent Research Results and Activities of Vijayan Gurumurthy Iyer", Sub Title: "Environmental Education and Research for Better Life", Abstracts of Selected papers and Bibliography By Vijayan G Iyer”, (ISBN-10: 3845405740, ISBN-13: 978-3-84540574-2) Edited By Tatiana Melnic LAP LAMBERT Academic Publishing GmbH Dudweiler Landstraße 9966123 Saarbrücken, Germany,116 p, Release Date 30 June 2011.

[5] Vijayan G.Iyer, (2007)“Environmental Science and Sustainable Development are The Basis of Environmental Education for the $21 \mathrm{St}$ Century”, Abstracts Book of the IV National Teacher's Science Conference 2007 (NTSC-2007), Theme entitled" Environmental Education for Better Life” ID number 1/Tamilnadu/17 organized by NCSTC-Network, New Delhi , Hosted by Pahal, Uttaranchal, Rajeev Gandhi Navodaya Vidyalaaya, Dehradun, www.ncstc-network.org, 2225 September 2007,pp.69-70.

[6] Vijayan G.Iyer, (2009) "Environmental Science and Sustainable Development are The Basis of Environmental Education in the $21 \mathrm{St}$ Century", Proceedings of the VII th International Conference on Challenges in Higher Education and Research in the 21 st Century, CDROM, English Language Faculty of Engineering, Technical University of Sofia, Recreation Hotel, Sozopol, Bulgaria, 2-5 June, 2009, http://elfe.tu-sofia.bg/cher21/program_2009.doc.

[7] Vijayan G.Iyer, (2009)“Some Innovative Practices on Quantity and Quality of Engineering Education and Research”, Proceedings of the VII th International conference on Challenges in Higher Education and Research in the 21 st Century, CD-ROM, English Language Faculty of Engineering, Technical University of Sofia , Recreation Hotel, Sozopol, Bulgaria, 2-5 June, 2009, http://elfe.tusofia.bg/cher21/program_2009/doc.

[8] Vijayan G.Iyer, et al. (2009), “Some Innovative Practices on Quantity and Quality of Engineering Education and Research”, Proceedings of the 6 th WSEAS International Conference on Engineering Education (EE '09), (ISBN:978-960-474-100-7, ISSN: 1790-2769), pp.97-107, Recent Advances in Engineering Education, Reference Book and Text Book of Mathematics and Computer Science in Engineering, Rodos Island, Greece, July, 22-24, 2009.

[9] Vijayan G.Iyer, et al.(2006), “Quantity and Quality in Engineering Education and Research”. Book of the Proceedings of the 3rd WSEAS International Conference on Engineering Education (ISSN:1790-5117, ISBN:960-8457-47-5), (EE’06), CD-ROM, WSEAS ID number 535-414, July 11-13, 2006, Vouliagmeni, Athens, Greece, pp. 97-107.

[10] Vijayan G.Iyer, et al.,(2006) "Efficient Methods to Improve the Productivity of a Teacher and Quality of Lectures in Teacher Educational Institutions”, Book of the Proceedings of the 3rd WSEAS International Conference on Engineering Education (ISSN:1790-5117, ISBN:960-8457-47-5), CD-ROM, ID: 535-413, July 11-13, 2006, Athens, Gr., pp. 73-96.

[11] Vijayan G.Iyer, et al.,(2009) ““'Some Innovative Practices on Quantity and Quality of Engineering Education and Research”, (AEBD’09), (ISSN:1790-5109, ISBN:978-960-474-091-8), pp. 237-252, WSEAS ID No. 617-121, La Laguna, Tenerife, Canary Islands, Spain, 1-3, July 2009, http://www.wseas.us/conferences/2009/lalaguna/wwai.

[12] Vijayan G.Iyer,(2003) "Efficient Methods to Improve the Productivity of a Teacher and Quality of Lectures in Teacher Educational Institutions", Proceedings of the National Seminar on Innovative Practices and Experiments in School Education and Teacher Education and All India
Competition on Innovative Experiments and Practices, April , 14-17, 2003, Department of Teacher Education \& Extension(DTEE), National Institute of Education (NIE), National Council of Educational Research \& Training, New Delhi, Ref. ETE-2.

[13] Vijayan G.Iyer,(2006)“Plenary lecture-III, Quantity and Quality in Engineering Education and Research”. Book of the Proceedings of the 3rd WSEAS International Conference on Engineering Education (ISSN:1790-5117, ISBN:960-8457-47-5), (EE’06), CD-ROM, WSEAS ID number 535-414, July 11-13, 2006, Vouliagmeni, Athens, Greece, pp. 97-107.

[14] Vijayan G.Iyer,(2006)“Quantity and Quality in Engineering Education and Research”, Program Book of the Seventh WFEO World Congress on Engineering Education: Mobility of Engineers, CD-ROM, Budapest in Hungary, World Federation of Engineering Organizations (WFEO), 4-8 March 2006, pp.14.

[15] Vijayan G.Iyer,(2007)“Environmental Science and Sustainable Development are The Basis of Environmental Education for the $21 \mathrm{St}$ Century”, Abstracts Book of the IV National Teacher's Science Conference 2007 (NTSC-2007), Theme entitled” Environmental Education for Better Life" ID number 1/Tamilnadu/17 organized by NCSTC-Network, New Delhi, Hosted by Pahal, Uttanchal, Rajeev Gandhi NavodayaVidyalaaya, Dehradun, www.ncstc-network.org, 22-25 September 2007,pp.69-70.

[16] Vijayan G.Iyer,(2013)“ Some Practical Hints on Sustainable Entrepreneurial Process”, In Proceedings of Second FEIAP Convention and International Conference entitled “ Engineering Initiatives for Sustainable Development Integrating Innovation and Ethics”, Federation of Engineering Institutions of Asia and Pacific (FEIAP) organized by The Institution of Engineers (India) and hosted by Andhra Pradesh State Centre, May, 8 -11, 2013, pp.177-185.

[17] Vijayan G.Iyer,(2013) "Some Practical Hints on Occupational Safety and Health Compliance Requirements in Industries", In Proceedings of Safety Conference 2013, Safety in Infrastructure Sector, 19-20 July 2013 Venue IE(I) Auditorium, Organized by the Institution of Engineers (India), Tamilnadu State Centre, 19 Swami Sivanadanda Salai, Chepauk, Chennai-5, pp.46.

[18] Vijayan G.Iyer,(2013) "The Sustainable Entrepreneurial Process to Starting an Enterprise from Scratch - Guidelines to Set up a Sustainable Enterprise”, In Abstract book of the 28 th Indian Engineering Congress (IEC), 2013, Technical Paper Session/Colloquium of Interdisciplinary Engineering on 22.12.2013) of Theme: "Engineering Advancements and Accelerated Nation Building Organized by the Institution of Engineers (India) Hosted by Tamilnadu State Centre at Hotel The Leela Palace, Chennai during December 20-22 , 2013, pp. 189.

[19] Vijayan G.Iyer,(2013), "Sustainable Entrepreneurship Education is A New Dimension in Higher Technical Education for Sustainability”, In Proceedings of 43 rd ISTE National Annual Convention 2013 Theme: "Empowering Technical Education to Address Sustainability and Global Competitiveness", Sub theme: New Dimensions in Higher Technical Education for Sustainability (ISBN: 978-93-5142-315-7) Organized by Indian Society for Technical Education-T.K. Institute of Engineering \&Technology, Warananagar, Tal: Panhala, Dist. Kolhapur-416 113 on 19-21 st December 2013.

[20] Iyer, Vijayan Gurumurthy, "Study of Sustainable Enterprise Creation Process towards Economic Development”, In Abstract Book of Ingenieria 2014 Latin America and Caribbean Congress and Exhibition, Argentina for the Subject Area: 1-1, Developing Economies (ECO's), Job No. 429 Poster Presentation on 3 rd November 2014 at 8:00-9:00 hrs held during 3-6, November 2014 at Centro Costo Salguero, Buenos Aires, Argentina, http://www.ingenieria2014.org/programa, Included in Congress Book of Proceedings for Engineering2014 at Argentina titled 'Building a Sustainable Regional Future'.

[21] Iyer, Vijayan Gurumurthy, "Policy Study of Education Coupled with Entrepreneurial Process for Sustainable Development “, In Abstract Book of Ingenieria 2014 Latin America and Caribbean Congress and Exhibition -Argentina for the Subject Area: 3.3, Educational and Professional Regional Integration(EPRI), Job No. 432 Poster presentation on 3 rd November 2014 at 09:00-10:00 hrs during 3-6, November 2014 at Centro Costo Salguero Buenos Aires, Argentina, http://www.ingenieria2014.org/programa, Full Paper Included in 
Congress Book of Proceedings for Engineering2014 at Argentina titled 'Building A Sustainable Regional Future'.

[22] Iyer Vijayan Gurumurthy (2017).“Strategic Environmental Assessment (SEA) Process for the Higher Education Institutions (HEIs) to Achieve Research and Academic Excellence”, Journal of Modern Education Review, ISSN 2155-7993,USA, December 2016, Volume 6, Number 12 ,PP. 958-970 (13 pages) @Academic Star Publishing Company, New York, USA, http://www.academicstar.us.

[23] Iyer Vijayan Gurumurthy (2016).“Environmental and Quality Management for the Higher Education Institutions to Achieve Research and Academic Excellence", Journal of Modern Education Review (JMER), ISSN 2155-7993,USA, February 2016, Volume 6, Number 2 , PP. 135-146 (12 pages) @Academic Star Publishing Company, New York, USA, http://www.academicstar.us.

[24] Iyer, Vijayan Gurumurthy.“ Education Coupled with Entrepreneurial Process Approach Towards Sustainable Development”, Journal titled Procedia-Social and Behavioral Sciences (ISSN: 1877-0428) Published by ScienceDirect, Elsevier Ltd., Oxford, UK, www.sciencedirect.com, 177 (2015) 147-161, PP 147-161.

[25] Iyer, Vijayan Gurumurthy (2017).“Self-Bibliographical References of Prof.(DL)Dr.Vijayan Gurumurthy Iyer, Sub title: "Sustainable SelfBibliographical References About Sustainable Literature by Prof.(D.SC.,LL.D.,DL) Dr. Vijayan Gurumurthy Iyer”, (ISBN-13: 9783-330-06124-8) ISBN-10: 3330061243 EAN: 9783330061248) Edited By Natalia Cojocar Acquisition Editor and published by LAP LAMBERT Academic Publishing of OmniScriptum GmbH \& Co. KG Bahnhofstraße 28, D-66111 Saarbrücken, Germany; $64.90 €$ Euro. Number of Pages 196. Published on 24.03.2017.

[26] Iyer, Vijayan Gurumurthy (2017). “Total Quality Management (TQM) in Education Sector and Its Implementation Framework Towards Sustainable National Development”. In the Technical Volume Proceedings of the 32 nd Indian Engineering Congress, Theme entitled "Innovation in Engineering: Competitive Strategy Perspective" (ISBN: 978-93-86724-29-8) held during 21 st-23 rd December 2017 at Chennai Organized by The Institution of Engineers (India) Published by Excel India Publishers, New Delhi, Proceedings page number 412-421.

[27] Iyer, Vijayan Gurumurthy. "Eco-Friendly Rubberized Cotton Fabric Roller Development for Cotton Roller Gins", "Proceedings of the World Engineers Convention (ISBN: 7-5046-3929-X), Volume 'E' 'Agricultural Engineering and Food Security ( ISBN 7-89995-986-1)', theme entitled "Engineers Shape the Sustainable Future", CD-ROM , 2-6 November 2004, Shanghai in China, China Association for Science and Technology (CAST) and World Federation of Engineering Organizations, China Science \& Technology Press”, pp. 105-114.

[28] Iyer, Vijayan Gurumurthy (2018) . “Total Quality Management (TQM) in Education Sector and Its Implementation Framework Towards Sustainable International Development”. In the Proceedings of the 2018 International Conference on Computer Science, Electronics and Communication Engineering held at Wuhan, China during February 7-8, 2018 as General Chair of CSECE2018 , http://www.csece2018.org, Book entitled "Advances in Computer Science Research (ACSR), Volume 80, ISSN: 2352-538X, ISBN 978-94-6252-487-3 Published by Editor Dr.Vijayan Gurumurthy Iyer, Editor of ACSR, doi:10.2991/csece-18.2018.119.

[29] Iyer, Vijayan Gurumurthy (2018) . “Total Quality Management (TQM) in Education Sector and Its Implementation Framework Towards Sustainable National Development”. In the Proceedings of the 2018 International Conference on Education Reform and Management Science held at Wuhan, China during April 22-23 Beijing, China as General Chair of ERMS2018 http://www.erms2018.org/ To be published by Atlantis Press (Print). 